This document is confidential and is proprietary to the American Chemical Society and its authors. Do not copy or disclose without written permission. If you have received this item in error, notify the sender and delete all copies.

\title{
Exfoliation of Graphite into Graphene in Aqueous Solutions of Inorganic Salts
}

\begin{tabular}{|r|l|}
\hline Journal: & Journal of the American Chemical Society \\
\hline Manuscript ID: & ja-2014-017156.R1 \\
\hline Manuscript Type: & Article \\
\hline Date Submitted by the Author: & 27-Mar-2014 \\
\hline Complete List of Authors: & $\begin{array}{l}\text { Parvez, Khaled; Max Planck Institute for Polymer Research, } \\
\text { Wu, Zhong-Shuai; Max Planck Institute for Polymer Research, } \\
\text { Li, Rongjin; Max Planck Institute for Polymer Research, } \\
\text { Liu, Xianjie; Linköping University, } \\
\text { Graf, Robert; Max Planck Institute for Polymer Research, } \\
\text { Feng, Xinliang; Max Planck Institute for Polymer Research, } \\
\text { Müllen, Klaus; Max-Planck-Institute for Polymer Research, }\end{array}$ \\
\hline
\end{tabular}

\section{SCHOLARONE ${ }^{\text {Th }}$ \\ Manuscripts}




\title{
Exfoliation of Graphite into Graphene in Aqueous
}

\section{Solutions of Inorganic Salts}

Khaled Parvez,,$^{\dagger}$ Zhong-Shuai Wu,,$^{\dagger}$ Rongjin Li, ${ }^{\dagger}$ Xianjie Liu, ${ }^{\dagger}$ Robert Graf,,$^{\dagger}$ Xinliang Feng, ${ }^{\dagger} \xi,{ }^{*}$ Klaus Müllen ${ }^{\dagger * *}$

${ }^{\dagger}$ Max Planck Institute for Polymer Research, Ackermannweg 10, Mainz 55128, Germany

$\$$ Department of Physics, Chemistry and Biology, Linköping University, SE-58183 Linköping, Sweden

$\S$ School of Chemistry and Chemical Engineering, Shanghai Jiao Tong University, 200240 Shanghai, P. R. China

*Address correspondence to muellen@mpip-mainz.mpg.de; feng@mpip-mainz.mpg.de

\begin{abstract}
:
Mass production of high-quality graphene sheets is essential for their practical application in electronics, optoelectronics, composite materials and energy-storage devices. Here we report a prompt electrochemical exfoliation of graphene sheets into aqueous solutions of different inorganic salts $\left(\left(\mathrm{NH}_{4}\right)_{2} \mathrm{SO}_{4}, \mathrm{Na}_{2} \mathrm{SO}_{4}, \mathrm{~K}_{2} \mathrm{SO}_{4}\right.$, etc). Exfoliation in these electrolytes leads to graphene with a high yield $(>85 \%, \leqslant 3$ layers), large lateral size (up to $44 \mu \mathrm{m}$ ), low oxidation degree (a C/O ratio of 17.2), and a remarkable hole mobility of $310 \mathrm{~cm}^{2} \mathrm{~V}^{-1} \mathrm{~s}^{-1}$. Further, highly conductive graphene films $\left(11 \Omega \mathrm{sq}^{-1}\right)$ are readily fabricated on an A4-size paper by applying brush painting of a concentrated graphene ink $(10 \mathrm{mg} / \mathrm{mL}$, in N,N'-dimethylformamide (DMF)).


All-solid-state flexible supercapacitors manufactured based on such graphene films deliver a high area capacitance of $11.3 \mathrm{mF} \mathrm{cm}^{-2}$ and an excellent rate capability of $5000 \mathrm{mV} \mathrm{s}^{-1}$. The described electrochemical exfoliation shows great promise for the industrial-scale synthesis of high-quality graphene for numerous advanced applications.

KEYWORDS: electrochemical exfoliation, high-quality graphene, electrolyte, graphene-ink, supercapacitor

\section{INTRODUCTION}

Graphene, a two-dimensional honeycomb $\mathrm{sp}^{2}$ carbon lattice, has received immense attention for its potential application in next-generation electronic devices, ${ }^{1,2}$ composite materials, ${ }^{3,4}$ energy storage devices, ${ }^{5}$ etc., due to its intriguing electrical, mechanical, and chemical properties. ${ }^{6,7}$ Mass production of high-quality, solution-processable graphene via a simple lowcost method, however, remains a major challenge. Several graphene preparation methods have been developed since its discovery. ${ }^{8}$ Among them, mechanically exfoliated and epitaxially grown graphene provides high-quality material, but in only limited quantities, for fundamental research $^{8,9}$. Chemical vapour deposition (CVD) using catalytic metal substrates such as $\mathrm{Ni}$ or $\mathrm{Cu}$, produces large-area high-quality graphene. ${ }^{9,10}$ The major obstacles to cost-effective industrialscale production of CVD-grown graphene, however, are the requirements of high temperature, a sacrificial metal, and multi-step transfer processes onto the desired substrates. Chemical exfoliation of graphite based on the Hummers method is an appealing route to produce solutionprocessable graphene oxide $(\mathrm{GO})$ in bulk-scale, but requires thermal or chemical reduction to partially restore the electronic properties of graphene. ${ }^{11}$ Several other methods have been developed to overcome these limitations, such as solvent- and/or surfactant-assisted liquid-phase exfoliation, ${ }^{12}$ electrochemical expansion, ${ }^{13}$ and formation of graphite intercalated compounds. ${ }^{14}$ 
Nevertheless, extensive sonication processes are indispensable for these methods, which limit the size and yield of thin graphene layers.

Recently, electrochemical exfoliation of graphite has attracted attention due to its easy, fast, and environmentally friendly nature to produce high-quality graphene. ${ }^{15-18}$ Electrochemical exfoliation of graphite has been performed mainly in two different types of electrolytes, i.e., ionic-liquids ${ }^{17,19}$ and aqueous acids (e.g., $\mathrm{H}_{2} \mathrm{SO}_{4}$ or $\left.\mathrm{H}_{3} \mathrm{PO}_{4}\right){ }^{15,18,20}$ Exfoliation in ionic liquids results in only a low yield of graphene with a small lateral size $(<5 \mu \mathrm{m})$, and is often functionalised with the ionic liquids, which disrupt the electronic properties of graphene. ${ }^{17,21}$ On the other hand, exfoliation in acidic electrolytes can yield graphene with a better quality and a larger lateral size, but a significant amount of oxygen-containing functional groups cannot be avoided due to the over-oxidation of graphite by the acid. ${ }^{15,18,20}$ Therefore, a proper electrolyte system that can balance the high-quality and large-quantity synthesis of exfoliated graphene (EG) is highly in demand.

In this work, we demonstrate a highly efficient electrochemical exfoliation of graphite in aqueous inorganic salts, such as ammonium sulphate $\left(\left(\mathrm{NH}_{4}\right)_{2} \mathrm{SO}_{4}\right)$, sodium sulphate $\left(\mathrm{Na}_{2} \mathrm{SO}_{4}\right)$, and potassium sulphate $\left(\mathrm{K}_{2} \mathrm{SO}_{4}\right)$. Under neutral $\mathrm{pH}$ conditions for electrochemical exfoliation, graphene sheets with the highest $\mathrm{C} / \mathrm{O}$ ratio of 17.2 (i.e., oxygen content of 5.5 atomic\% [at $\%$ ]) and lowest defect density were obtained. The EG sheets were readily produced on a scale of tens of grams, with $\sim 80 \%$ of the flakes larger than $5 \mu \mathrm{m}$, and $\sim 85 \%$ of flakes having 1 to 3 layers. Moreover, single-layer graphene sheets had a high hole mobility of $310 \mathrm{~cm}^{2} \mathrm{~V}^{-1} \mathrm{~s}^{-1}$ with a sheet resistance of $1.96 \mathrm{k} \Omega \mathrm{sq}^{-1}$, which is superior to the chemically reduced graphene oxide (rGO). The high solution-processability of EG further allowed for the preparation of concentrated graphene ink in $N, N^{\prime}$-dimethylformamide (DMF) without any additional surfactants. A simple 
paintbrush application of EG-ink to A4-sized paper yielded highly conductive $\left(\sim 11 \Omega\right.$ sq. $^{-1}$ with $0.74 \mathrm{mg} \mathrm{cm}^{-2}$ EG loading), mechanically stable, and large-area graphene films. All-solid-state flexible supercapacitors fabricated based on such graphene paper exhibited a high-area capacity of $11.3 \mathrm{mF} \mathrm{cm}^{-2}$ (at a scan rate of $1 \mathrm{mV} \mathrm{s}^{-1}$ ) and a high rate capability (up to $5000 \mathrm{mV} \mathrm{s}^{-1}$ ).

\section{RESULTS AND DISCUSSION}

Graphene preparation by electrochemical exfoliation. Electrochemical exfoliation of graphite was performed in a two-electrode system using platinum as the counter electrode and a graphite flake as the working electrode. Different types of aqueous inorganic salt electrolyte solutions were examined and among them sulphate-containing salts such as $\left(\mathrm{NH}_{4}\right)_{2} \mathrm{SO}_{4}$ exhibited the best exfoliation efficiency. Electrolyte solutions were prepared by dissolving $\left(\mathrm{NH}_{4}\right)_{2} \mathrm{SO}_{4}$ in water (concentration of $0.1 \mathrm{M}$ and $\mathrm{pH} \sim 6.5-7.0$ ). When a direct current (DC) voltage of $+10 \mathrm{~V}$ was applied to a graphite electrode, the graphite flakes began to dissociate and disperse into the electrolyte solution (Fig. 1a). The voltage was kept constant for 3 to 5 min to complete the exfoliation process. Afterwards, the exfoliated product was collected by vacuum filtration and repeatedly washed with water to remove any residual salts. The yield of the exfoliated EG flakes was more than $75 \%$ relative to the total weight of the starting graphite electrode. The collected powder was then dispersed in DMF by sonication for $10 \mathrm{~min}$. Thus, a dispersion of $\sim 2.5 \mathrm{mg} / \mathrm{mL}$ was obtained, which was stable for 3 weeks without apparent agglomeration (Fig. 1b). Remarkably, the exfoliation process could be readily scaled up depending on the type and size of the graphite electrode used (Fig. S1). For example, in a series of electrochemical experiments, $\sim 16.3 \mathrm{~g}$ of graphene sheets was obtained (Fig. 1c) within 30 min using three graphite foils (each with a dimension of $11.5 \mathrm{~cm} \times 2.5 \mathrm{~cm}$ ) simultaneously (Fig. S1a). 
In addition to $\left(\mathrm{NH}_{4}\right)_{2} \mathrm{SO}_{4}$, various aqueous electrolyte solutions of inorganic salts, such as $\mathrm{NH}_{4} \mathrm{Cl}, \mathrm{Na}_{2} \mathrm{SO}_{4}, \mathrm{NaNO}_{3}, \mathrm{~K}_{2} \mathrm{SO}_{4}$, and $\mathrm{NaClO}_{4}$ were examined in the electrochemical exfoliation process (see Fig. S2-S3 and Table S1 for details). Salts containing anions, such as $\mathrm{ClO}_{4}^{-}, \mathrm{Cl}^{-}$, and $\mathrm{NO}_{3}^{-}$, had no apparent exfoliation effects. Expansion of the graphite electrode was only observed when using $\mathrm{ClO}_{4}{ }^{-}$and $\mathrm{NO}_{3}^{-}$anions. In contrast, salts containing sulphate anions (e.g., $\mathrm{SO}_{4}{ }^{2-}$ ) exhibited pronounced exfoliation efficiency. Thin graphene sheets were readily obtained in less than 5 min (Fig. S2d,e and Fig. S3). The superior exfoliation efficiency of sulphate salts compared to other anions can be attributed to the lower reduction potential of $\mathrm{SO}_{4}{ }^{2-}(+0.20 \mathrm{~V})$ to generate $\mathrm{SO}_{2}$ gas. In contrast, the reduction potential of $\mathrm{ClO}_{4}{ }^{-}$and $\mathrm{NO}_{3}{ }^{-}$ions to produce $\mathrm{Cl}_{2}$ and NO gases is as high as 1.42 and $0.96 \mathrm{~V}$, respectively (see Scheme S1 for details).

We propose the mechanism of electrochemical exfoliation depicted in Fig. 1d: (i) Applying bias voltage results in a reduction of water at the cathode, creating hydroxyl ions $\left(\mathrm{OH}^{-}\right)$that act as a strong nucleophile in the electrolyte. The nucleophilic attack of graphite by $\mathrm{OH}^{-}$ions initially occurs at the edge sites and grain boundaries. (ii) Oxidation at the edge sites and grain boundaries then leads to depolarization and expansion of the graphite layers, thereby facilitating the intercalation of sulphate ions $\left(\mathrm{SO}_{4}{ }^{2-}\right)$ within the graphitic layers. During this stage, water molecules may co-intercalate with the $\mathrm{SO}_{4}{ }^{2-}$ anions. (iii) Reduction of $\mathrm{SO}_{4}{ }^{2-}$ anions and selfoxidation of water produce gaseous species such as $\mathrm{SO}_{2}, \mathrm{O}_{2}$, and others, as evidenced by the vigorous gas evolution during the electrochemical process. ${ }^{22,23}$ These gaseous species can exert large forces on the graphite layers, which are sufficient to separate weakly bonded graphite layers from one another. ${ }^{24}$ This hypothesis was confirmed by controlled experiments in which a constant bias voltage $($ e.g., $+10 \mathrm{~V})$ was applied to graphite electrodes for different time periods ( 5 to $60 \mathrm{~s}$ ), and changes in the morphology of the graphite foil were monitored by scanning 
electron microscopy (SEM) and optical microscopy. SEM images of both the surface and edge of the original graphite show closely packed layers (Fig. 2a-c). When voltage was applied, however, the surface and edge morphology changed drastically within a few seconds (Fig. S4). After applying voltage for $5 \mathrm{~s}$, the edge of the graphite foil expanded and the cracks in the graphite layers increased (Fig. S5b and c). When the time was increased from 5 to $60 \mathrm{~s}$, a large amount of graphene flakes was exfoliated and dispersed into the electrolyte solution. After $60 \mathrm{~s}$, the edge of the graphite foil expanded to almost 10 times that in the initial state (Fig. 2b, h). Moreover, a network of ripples on the surface of the graphite was clearly identified in the SEM images (Fig. 2d,g and Fig. S5a,d), which might be due to the visible gas evolution causing expansion and swelling of the graphite layers. These observations strongly support our hypothesis that during the electrochemical process, edge and grain boundaries of the graphite electrode open up first, which facilitates anion intercalation and results in exfoliated graphene sheets. A detailed reaction mechanism on the oxidation, i.e., oxide bond formation of graphite, is proposed and discussed in the Supplementary Information (Scheme S2).

We further investigated the effect of the electrolyte concentration on the applied potential for graphite exfoliation. The voltage or potential for graphite exfoliation decreased upon increasing the concentration of $\left(\mathrm{NH}_{4}\right)_{2} \mathrm{SO}_{4}$ (Fig. S6a). When the concentration of $\left(\mathrm{NH}_{4}\right)_{2} \mathrm{SO}_{4}$ was lower than $0.01 \mathrm{M}$, the yield of EG was less than $5 \mathrm{wt} \%$, indicating a limited amount of ions available for graphite intercalation. In sharp contrast, when the concentration increased from 0.01 to $1.0 \mathrm{M}$, a high yield of $\mathrm{EG}(>75 \mathrm{wt} \%)$ was obtained. A further increase in the concentration (e.g., 3.0 and $5.0 \mathrm{M})$, however, failed to enhance the graphene yield $(<50 \%$, Fig. $\mathrm{S} 6 \mathrm{~b})$. As discussed above, the initial oxidation of graphite by $\mathrm{OH}^{-}$ions at the edge and/or grain boundaries is essential for the depolarization and expansion of the graphite layers as well as for 
the following anion intercalation. With the high concentration of $\left(\mathrm{NH}_{4}\right)_{2} \mathrm{SO}_{4}$, the formation of $\mathrm{OH}^{-}$ions is suppressed due to the low water content, therefore, the graphite edge oxidation, expansion, and $\mathrm{SO}_{4}{ }^{2-}$ ion intercalation processes are expected to be relatively slow.

Morphological and structural characterizations of EG. The morphology of the EG sheets was investigated by SEM and atomic force microscopy (AFM). EG nanosheets were deposited on $\mathrm{SiO}_{2}$ substrates using the Langmuir-Blodgett technique (Fig. S7a). Figure 3a shows a SEM image of a typical EG sheet $(18.7 \mu \mathrm{m})$. Lateral size measurements of $120 \mathrm{EG}$ sheets reveal that over $80 \%$ of the EG sheets are larger than $5.0 \mu \mathrm{m}$ (Fig. 3b), and the largest flake size observed is $\sim 44.0 \mu \mathrm{m}$ (Fig. S7b). A histogram of flake thickness acquired across EG flakes using AFM shows a mean thickness of $\sim 0.72 \mathrm{~nm}$ (Fig. 3c), confirming the monolayer nature, which is comparable with the thickness of pristine graphene on a Si wafer ${ }^{25}$. The measured thickness of a bilayer and a multi-layer ( $\geq 4$ layers) $\mathrm{EG}$ is 1.30 and $3.11 \mathrm{~nm}$, respectively (Fig. S8). The thickness distribution of more than 50 sheets calculated from the AFM height profile is presented in Fig. 3d. Remarkably, more than $85 \%$ of EG nanosheets comprises thin graphene ( $\leq 3$ layers), where single and bi-layer graphenes are the dominant products (together $\sim 72 \%$ ). Highresolution transmission electron microscopic (HRTEM) images further disclose that the EG sheets range from a single layer to four layers (Fig. 3e and S9). The selected area electron diffraction (SAED) pattern in Figure $3 f$ exhibits a typical six-fold symmetric diffraction with stronger diffraction from (1-210) plane than from the (0-110) plane, indicating the high crystallinity of a bilayer graphene sheet. ${ }^{13,26}$

We then used Raman spectroscopy to identify defects in the graphene ${ }^{27,28}$. We performed Raman spectroscopy and mapping with a 532-nm excitation laser on EG deposited on $\mathrm{SiO}_{2} / \mathrm{Si}$ substrates. Raman mapping of D and G peaks from a few layer EG sheet (2 - 4 layers; selected 
layers are shown in Fig. 4a) was extracted and plotted in Fig. 3b and c, respectively. The D peak $\left(\sim 1350 \mathrm{~cm}^{-1}\right)$ was caused by the breathing mode of the $\mathrm{sp}^{2}$ carbon atoms and activated by the existence of defects such as edges, functional groups, or structural disorders ${ }^{29}$. The intensity contrast in the colour scale in Fig. $4 \mathrm{~b}$ and $\mathrm{c}$ shows that the intensity of the G peak is more than two times that of $\mathrm{D}$ peak (mean $I_{D} / I_{G}$ ratio $=0.42$ ), indicating a low degree of defects. The corresponding Raman spectra in Fig. 4d (measured near the centre of the graphene flake) demonstrates an $I_{D} / I_{G}$ ratio of 0.25 , which is much smaller than for chemically or thermally reduced GO $(\sim 1.1 \text { to } 1.5)^{30}$, and electrochemically exfoliated graphene (0.4) in acidic solution ${ }^{15}$.

X-ray photoelectron spectroscopy (XPS) was used to probe the chemical composition of the as-prepared EG. The EG showed approximately 5.5 at\% oxygen content on graphene (Fig. S10), which was much lower than that obtained in acidic electrolyte solution (i.e., 7.5 at $\%$ ). ${ }^{15}$ Despite the presence of a tiny amount of oxygen originating from the oxidation of graphite by $\mathrm{OH}^{-}$ions during the electrochemical process, the $\mathrm{C} / \mathrm{O}$ ratio of 17.2 for $\mathrm{EG}$ was significantly higher than those reported for $\mathrm{EG}$ and $\mathrm{rGO} \cdot{ }^{15,31,32}$ A detailed comparison of the $\mathrm{C} / \mathrm{O}$ ratios between $\mathrm{rGO}$ and different types of exfoliated graphene is presented in Table S2. The deconvoluted XPS spectra of the $\mathrm{C} 1 \mathrm{~s}$ peak (Fig. 5a) disclose the presence of $3.64 \mathrm{at} \%$ of $\mathrm{C}-\mathrm{OH}(285.5 \mathrm{eV}), 0.38 \mathrm{at} \%$ of $\mathrm{C}=\mathrm{O}$ $(287.6 \mathrm{eV})$, and $1.48 \mathrm{at} \%$ of $\mathrm{C}(\mathrm{O})-\mathrm{O}(290.1 \mathrm{eV})$ groups.

Further structural analysis of EG by ${ }^{13} \mathrm{C}$ magic angle spinning (MAS) NMR revealed a broad signal centred at $122 \mathrm{ppm}$ (graphitic, $\mathrm{C} \mathrm{sp}^{2}$ ), indicating the presence of pure $\mathrm{sp}^{2}$ hybridised carbon sites (Fig. S11). In contrast, the NMR spectrum of GO showed an additional signal of $\mathrm{sp}^{3}$ hybridised carbons bound to oxygen (C-OH or C-O-C) in the range of 60 to $70 \mathrm{ppm}$. The signal of EG at $122 \mathrm{ppm}$ was quite broad when compared to that of GO. This can be attributed to the high conductivity of EG, resulting in a higher number of perturbing magnetic moments of the 
free charges. The spinning of the EG sample in the magnetic field was difficult because of the high conductivity, which also limited the filling of MAS rotors.

The powder X-ray diffraction pattern of EG displayed a peak at $26.3^{\circ}$ ( $d$-spacing $3.48 \AA$; Fig. S12). The presence of a small amount of functional groups in EG acts as a spacer between layers and results in a lower $2 \theta$ angle with large $d$-spacing compared to graphite $\left(26.5^{\circ}, d\right.$ spacing $~ 3.36 \AA)$, but significantly higher than $\operatorname{rGO}\left(25.0^{\circ}, d\right.$-spacing $\left.\sim 3.56 \AA\right) . .^{31}$ Figure $5 \mathrm{~b}$ displays the ultraviolet photoelectron spectra around the secondary-electron threshold region for a thin film of EG. The measured work function $\left(\Phi_{\mathrm{EG}}\right)$ of $\mathrm{EG}$ was $4.57 \mathrm{eV}$, slightly higher than that of pristine graphene $(\sim 4.50 \mathrm{eV}) .^{33}$ This can be attributed to the presence of oxygencontaining functional groups in EG that can produce surface dipoles via the extraction of $\pi$ electrons from graphene. ${ }^{34}$

Electronic properties of EG. To examine the electronic properties of the as-prepared EG flakes, we fabricated field-effect transistor (FET) devices based on thin EG film (thickness $\sim 0.7$ - $4 \mathrm{~nm}$ ) and a single-layer EG sheet (thickness $\sim 0.71 \mathrm{~nm}$ ), respectively (Fig. S13). Both thin EG film and isolated single-layer $\mathrm{EG}$ on $\mathrm{SiO}_{2} / \mathrm{Si}$ substrates were prepared by using the Langmuir-Blodgett technique. The detailed device fabrication is described in the experimental section. The transfer curves of the FET devices based on thin EG film and single-layer EG are presented in Fig. 6a and c, respectively. Notably, the device based on thin EG film (Fig. 6a,b) possesses a maximum hole mobility of $98.2 \mathrm{~cm}^{2} \mathrm{~V}^{-1} \mathrm{~s}^{-1}$, whereas single-layer EG (Fig. 6c) gives an excellent hole mobility of $\sim 310 \mathrm{~cm}^{2} \mathrm{~V}^{-1} \mathrm{~s}^{-1}$ and a sheet resistance of $1.96 \mathrm{k} \Omega \mathrm{sq}^{-1}$ (Fig. 6d), comparable with undoped CVD-grown graphene $\left(1.05 \mathrm{k} \Omega \mathrm{sq}^{-1}\right)^{35}$. The lower mobility of the thin film device can be attributed to the interjunction resistance between EG flakes. It should be emphasised that the hole mobility of single-layer EG achieved in this work is significantly higher than that of 
chemically reduced GO $\left(123 \mathrm{~cm}^{2} \mathrm{~V}^{-1} \mathrm{~s}^{-1}\right)^{31}$ or electrochemically exfoliated graphene in acidic solution (233 $\left.\mathrm{cm}^{2} \mathrm{~V}^{-1} \mathrm{~s}^{-1}\right)^{15}$ (see Table $\mathrm{S} 3$ for detailed comparison).

EG thin films on plastic substrate. The high-quality and solution-processability of EG allow for fabricating transparent graphene films on flexible polyethylene terephthalate (PET) substrates by a vacuum filtration and dry transfer method (Fig. S14a). ${ }^{15}$ Briefly, an EG dispersion of 0.1 $\mathrm{mg} / \mathrm{mL}$ in DMF was vacuum-filtered through a polytetrafluoroethylene (PTFE) membrane followed by mechanically pressing the filtered film against a PET substrate. Afterwards, the PTFE membrane was peeled off, leaving the transferred EG film on the substrate due to van der Waals interaction between the substrate and graphene. The thickness of the transferred EG film could be adjusted by controlling the filtration volume and the concentration of EG dispersions. For example, vacuum filtration of 3 and $9 \mathrm{~mL}$ of EG dispersions resulted in $\sim 6.0$ and $\sim 16.0 \mathrm{~nm}$ graphene films on PET with $\sim 91 \%$ and $\sim 80 \%$ transparency, respectively (Fig. S14b). The sheet resistance $\left(R_{\mathrm{S}}\right)$ measured by a four-point probe system revealed a mean value of 24.2 and 7.56 $\mathrm{k} \Omega \mathrm{sq}^{-1}$ for 6.0 and $16.0 \mathrm{~nm}$ films, respectively. Low temperature annealing (i.e., $300^{\circ} \mathrm{C}$ ) of the EG films decreased the $R_{\mathrm{s}}$ to 7.61 and $1.81 \mathrm{k} \Omega \mathrm{sq}^{-1}$, respectively (Fig. S14c). Remarkably, further doping the EG films with $65 \% \mathrm{HNO}_{3}$ for $2 \mathrm{~h}$ led to $R_{\mathrm{s}}$ values of 0.87 and $0.33 \mathrm{k} \Omega$ sq. ${ }^{-1}$, respectively, without sacrificing the original transparency (Fig. S15).

EG ink-coated paper for flexible supercapacitors. We further demonstrated the use of EG as conductive ink, which is an important requirement for next-generation printable electronics. Towards this end, a conductive graphene ink was prepared by dispersing EG flakes in DMF with a high concentration (10 mg/mL; Fig. 7a). Application of the as-prepared graphene ink on A4size paper using a paintbrush (Fig. 7b) easily transformed the paper into an electrically conductive sheet. The bonding of cellulose fiber in paper produces many air passages or pores 
throughout the paper (Fig. S16a). Thus, the highly porous nature of paper provides a strong capillary force for the EG ink, enhancing solvent absorption and leading to a conformal coating of EG ink on paper (Fig. S16b). Moreover, a simple film adhesion test with a piece of cellophane tape demonstrated strong adhesion between the EG and paper, confirming high film stability against damage, such as scratching or peeling off (Fig. 7c). Figure $7 d$ presents the relationship between the paper resistance and the amount of EG loading (in $\mathrm{mg} \mathrm{cm}^{-2}$ ). A sheet resistance of $\sim 11 \Omega$ sq. $^{-1}$ was obtained with an EG loading of $0.74 \mathrm{mg} \mathrm{cm}^{-2}$, comparable to carbon nanotube paper. ${ }^{36}$ Moreover, the graphene paper possessed excellent mechanical properties since after bending to a 4-mm radius, there was no significant change in electrical conductivity (Fig. 7e).

To demonstrate the multifunction of the EG paper, we explored the potential of EG-coated paper for all solid-state flexible supercapacitors. For this purpose, a polyvinyl alcohol $/ \mathrm{H}_{2} \mathrm{SO}_{4}$ gel was drop-cast onto the top surface of EG-coated paper (with a loading of $\sim 0.60 \mathrm{mg} \mathrm{cm}^{-2}$ ) and solidified overnight. Afterwards, two pieces of EG paper electrodes were integrated into an allsolid-state supercapacitor without using an additional current collector (Fig. 8a). The electrochemical properties of the as-fabricated device were investigated by cyclic voltammetry. The binder- and additive-free fabricated EG paper-based supercapacitor exhibited typical doublelayer capacitive behaviour at various scan rates (Fig. $8 \mathrm{~b}$ and $\mathrm{S} 17 \mathrm{a}$ ). The area capacitance of the flexible EG paper supercapacitor was $\sim 11.3 \mathrm{mF} \mathrm{cm}^{-2}$ at a low scan rate of $1 \mathrm{mV} \mathrm{s}^{-1}$ (Fig. 8d), comparable to or even higher than thin-film rGO or carbon nanotubes on flexible substrates. ${ }^{37,38}$ In addition, the gravimetric capacitance calculated based on the area capacitance ranges from 18.8 to $56.6 \mathrm{~F} \mathrm{~g} \mathrm{~g}^{-1}$, depending of the loading of EG on paper varying from 0.6 to $0.2 \mathrm{mg} \mathrm{cm}^{-2}$, respectively (Fig. S17). Remarkably, the device exhibited high rate capability that could be 
operated up to $5000 \mathrm{mV} \mathrm{s}^{-1}$ (Fig. 8c). The rate capability achieved in this work was thus superior to that of carbon nanotubes and/or rGO-coated cellulose paper supercapacitors. ${ }^{37,39-42}$

\section{CONCLUSION:}

Taken together, our electrochemical exfoliation of graphite in aqueous sulphate salt electrolyte solution effectively reduces the oxidation degree and thereby significantly improves the chemical and electronic properties of graphene. Thin-layer graphene sheets were obtained at a high yield with large flake size and can be produced on a scale of tens of grams, demonstrating the great potential for industrial scale-up production. The $\mathrm{EG}$ has the highest $\mathrm{C} / \mathrm{O}$ ratio (17.2) and hole mobility $\left(\sim 310 \mathrm{~cm}^{2} \mathrm{~V}^{-1} \mathrm{~s}^{-1}\right)$ among all the reported values of EG obtained in acidic electrolytes and solution-processed rGO. The solution-processability of high-quality EG in organic solvents permits their direct use in transparent films and conductive ink, providing great advantage for the fabrication of graphene-based materials and devices. Low-cost and environmentally-friendly production of such high-quality graphene is important, not only for future generation electronics but also for large-scale applications, such as composite materials, supercapacitors, fuel-cells, and batteries.

Acknowledgement: This work was financially supported by ERCF grants on NANOGRAPH and 2DMATER, DFG Priority Program SPP 1459, EU Project GENIUS, MOLESOL and EC under Graphene Flagship (No. CNECT-ICT-604391).

Supporting Information Available: Experimental details, photographs of electrochemical exfoliation in large-scale and in different electrolyte systems, AFM, HRTEM and optical microscopic images, XPS, solid-state NMR spectra and XRD of EG; AFM image of EG FET 
device, UV-Vis and sheet resistance of EG thin film before and after acid doping; SEM image of EG coated paper and electrochemical characterizations of EG paper based supercapacitors; summary of electrochemical exfoliation in different inorganic salts and comparison of elemental analysis and mobility of EG with different types of graphene. This material is available free of charge via the Internet at http://pubs.acs.org.

\section{REFERENCES}

(1) Wang, Y.; Chen, X.; Zhong, Y.; Zhu, F.; Loh, K. P. Appl. Phys. Lett. 2009, 95, 063302.

(2) Bae, S.; Kim, H.; Lee, Y.; Xu, X. F.; Park, J. S.; Zheng, Y.; Balakrishnan, J.; Lei, T.; Kim, H. R.; Song, Y. I.; Kim, Y. J.; Kim, K. S.; Ozyilmaz, B.; Ahn, J. H.; Hong, B. H.; Iijima, S. Nat. Nanotechnol. 2010, 5, 574.

(3) Wu, D. Q.; Zhang, F.; Liang, H. W.; Feng, X. L. Chem. Soc. Rev. 2012, 41, 6160.

(4) Parvez, K.; Yang, S. B.; Hernandez, Y.; Winter, A.; Turchanin, A.; Feng, X. L.; Müllen, K. ACS Nano 2012, 6, 9541.

(5) Wu, Z. S.; Parvez, K.; Feng, X.; Müllen, K. Nat. Commun. 2013, 4, 2487.

(6) Geim, A. K.; Novoselov, K. S. Nat. Mater. 2007, 6, 183.

(7) Park, S.; Ruoff, R. S. Nat. Nanotechnol. 2009, 4, 217.

(8) Novoselov, K. S.; Geim, A. K.; Morozov, S. V.; Jiang, D.; Zhang, Y.; Dubonos, S. V.; Grigorieva, I. V.; Firsov, A. A. Science 2004, 306, 666.

(9) Sutter, P. W.; Flege, J. I.; Sutter, E. A. Nat. Mater. 2008, 7, 406.

(10) Lee, Y.; Bae, S.; Jang, H.; Jang, S.; Zhu, S. E.; Sim, S. H.; Song, Y. I.; Hong, B. H.; Ahn, J. H. Nano Lett. 2010, 10, 490. 
(11) Eda, G.; Fanchini, G.; Chhowalla, M. Nat. Nanotechnol. 2008, 3, 270.

(12) Hernandez, Y.; Nicolosi, V.; Lotya, M.; Blighe, F. M.; Sun, Z. Y.; De, S.; McGovern, I. T.; Holland, B.; Byrne, M.; Gun'ko, Y. K.; Boland, J. J.; Niraj, P.; Duesberg, G.; Krishnamurthy, S.; Goodhue, R.; Hutchison, J.; Scardaci, V.; Ferrari, A. C.; Coleman, J. N. Nat. Nanotechnol. 2008, 3, 563.

(13) Wang, J. Z.; Manga, K. K.; Bao, Q. L.; Loh, K. P. J. Am. Chem. Soc. 2011, 133, 8888.

(14) Shih, C. J.; Vijayaraghavan, A.; Krishnan, R.; Sharma, R.; Han, J. H.; Ham, M. H.; Jin, Z.; Lin, S. C.; Paulus, G. L. C.; Reuel, N. F.; Wang, Q. H.; Blankschtein, D.; Strano, M. S. Nat. Nanotechnol. 2011, 6, 439.

(15) Parvez, K.; Li, R. J.; Puniredd, S. R.; Hernandez, Y.; Hinkel, F.; Wang, S. H.; Feng, X. L.; Müllen, K. ACS Nano 2013, 7, 3598.

(16) Lee, J. H.; Shin, D. W.; Makotchenko, V. G.; Nazarov, A. S.; Fedorov, V. E.; Kim, Y. H.; Choi, J. Y.; Kim, J. M.; Yoo, J. B. Adv. Mater. 2009, 21, 4383.

(17) Liu, N.; Luo, F.; Wu, H. X.; Liu, Y. H.; Zhang, C.; Chen, J. Adv. Funct. Mater. 2008, 18, 1518.

(18) Su, C. Y.; Lu, A. Y.; Xu, Y. P.; Chen, F. R.; Khlobystov, A. N.; Li, L. J. ACS Nano 2011, $5,2332$.

(19) Lu, J.; Yang, J. X.; Wang, J. Z.; Lim, A. L.; Wang, S.; Loh, K. P. ACS Nano 2009, 3, 2367.

(20) Liu, J. L.; Yang, H. P.; Zhen, S. G.; Poh, C. K.; Chaurasia, A.; Luo, J. S.; Wu, X. Y.; Yeow, E. K. L.; Sahoo, N. G.; Lin, J. Y.; Shen, Z. X. Rsc. Adv. 2013, 3, 11745.

(21) Shang, N. G.; Papakonstantinou, P.; Sharma, S.; Lubarsky, G.; Li, M. X.; McNeill, D. W.; Quinn, A. J.; Zhou, W. Z.; Blackley, R. Chem. Commun. 2012, 48, 1877.

(22) Beck, F.; Jiang, J.; Krohn, H. J Electroanal. Chem. 1995, 389, 161. 
(23) Beck, F.; Junge, H.; Krohn, H. Electrochim. Acta 1981, 26, 799.

(24) Goss, C. A.; Brumfield, J. C.; Irene, E. A.; Murray, R. W. Anal. Chem. 1993, 65, 1378.

(25) Cheng, Z. G.; Zhou, Q. Y.; Wang, C. X.; Li, Q. A.; Wang, C.; Fang, Y. Nano Lett. 2011, 11, 767 .

(26) Sun, Z. Z.; Yan, Z.; Yao, J.; Beitler, E.; Zhu, Y.; Tour, J. M. Nature 2010, 468, 549.

(27) Yu, Q. K.; Jauregui, L. A.; Wu, W.; Colby, R.; Tian, J. F.; Su, Z. H.; Cao, H. L.; Liu, Z. H.; Pandey, D.; Wei, D. G.; Chung, T. F.; Peng, P.; Guisinger, N. P.; Stach, E. A.; Bao, J. M.; Pei, S. S.; Chen, Y. P. Nat. Mater. 2011, 10, 443.

(28) Malard, L. M.; Pimenta, M. A.; Dresselhaus, G.; Dresselhaus, M. S. Phys. Rep. 2009, 473, 51.

(29) Ferrari, A. C.; Meyer, J. C.; Scardaci, V.; Casiraghi, C.; Lazzeri, M.; Mauri, F.; Piscanec, S.; Jiang, D.; Novoselov, K. S.; Roth, S.; Geim, A. K. Phys. Rev. Lett. 2006, 97, 187401.

(30) Buglione, L.; Chng, E. L. K.; Ambrosi, A.; Sofer, Z.; Pumera, M. Electrochem. Commun. 2012, 14,5 .

(31) Feng, H.; Cheng, R.; Zhao, X.; Duan, X.; Li, J. Nat. Commun. 2013, 4, 1539.

(32) Moon, I. K.; Lee, J.; Ruoff, R. S.; Lee, H. Nat. Commun. 2010, 1, 73.

(33) Shin, H. J.; Choi, W. M.; Choi, D.; Han, G. H.; Yoon, S. M.; Park, H. K.; Kim, S. W.; Jin, Y. W.; Lee, S. Y.; Kim, J. M.; Choi, J. Y.; Lee, Y. H. J. Am. Chem. Soc. 2010, 132, 15603.

(34) Li, S. S.; Tu, K. H.; Lin, C. C.; Chen, C. W.; Chhowalla, M. ACS Nano 2010, 4, 3169.

(35) Kholmanov, I. N.; Magnuson, C. W.; Aliev, A. E.; Li, H. F.; Zhang, B.; Suk, J. W.; Zhang, L. L.; Peng, E.; Mousavi, S. H.; Khanikaev, A. B.; Piner, R.; Shvets, G.; Ruoff, R. S. Nano Lett. 2012, 12, 5679. 
(36) Hu, L.; Choi, J. W.; Yang, Y.; Jeong, S.; La Mantia, F.; Cui, L. F.; Cui, Y. Proc. Natl. Acad. Sci. U S A 2009, 106, 21490.

(37) Yoo, J. J.; Balakrishnan, K.; Huang, J. S.; Meunier, V.; Sumpter, B. G.; Srivastava, A.; Conway, M.; Reddy, A. L. M.; Yu, J.; Vajtai, R.; Ajayan, P. M. Nano Lett 2011, 11, 1423.

(38) Kaempgen, M.; Chan, C. K.; Ma, J.; Cui, Y.; Gruner, G. Nano Lett 2009, 9, 1872.

(39) Hu, S.; Rajamani, R.; Yu, X. Appl. Phys. Lett. 2012, 100, 104103.

(40) Weng, Z.; Su, Y.; Wang, D. W.; Li, F.; Du, J. H.; Cheng, H. M. Adv. Energy. Mater. 2011, 1,917 .

(41) Kang, Y. J.; Chun, S. J.; Lee, S. S.; Kim, B. Y.; Kim, J. H.; Chung, H.; Lee, S. Y.; Kim, W. ACS Nano 2012, 6, 6400.

(42) Kang, Y. J.; Chung, H.; Han, C. H.; Kim, W. Nanotechnology 2012, 23, 065401. 

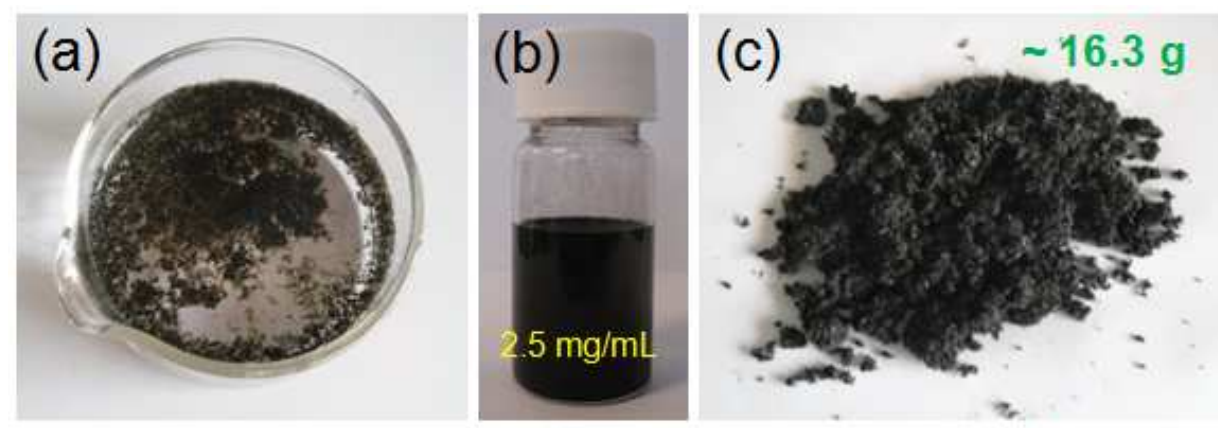

(d)

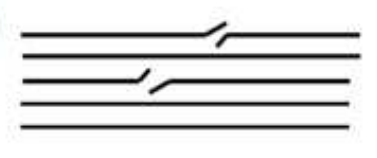

Graphite

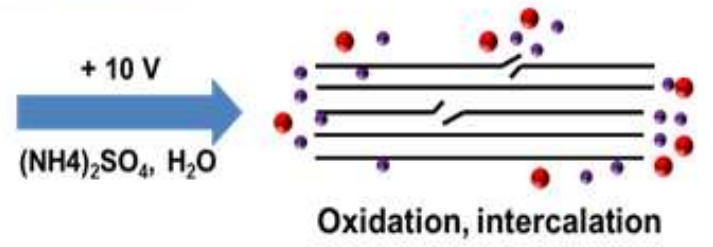

- $\mathrm{H}_{2} \mathrm{O} \bullet \mathrm{SO}_{4}{ }^{2 \cdot} \bigcirc \mathrm{O}_{2} \odot \mathrm{Co} \bigcirc \mathrm{sO}_{2}$

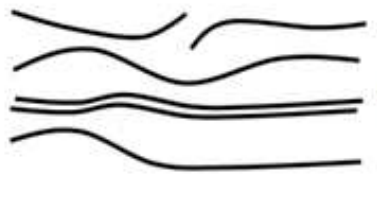

Exfoliated graphene

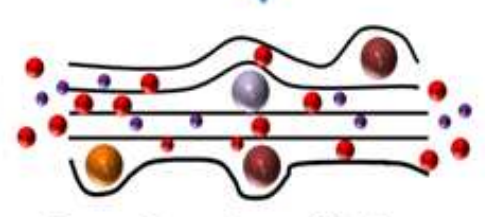

Expansion of graphite layers

Figure 1. Photograph of (a) graphite flakes after electrochemical exfoliation, (b) dispersed EG in DMF solution (concentration $\sim 2.5 \mathrm{mg} / \mathrm{mL}$ ), (c) EG powders in a bulk scale ( $16.3 \mathrm{~g}$ ). (d) Schematic illustration of the mechanism of electrochemical exfoliation. 

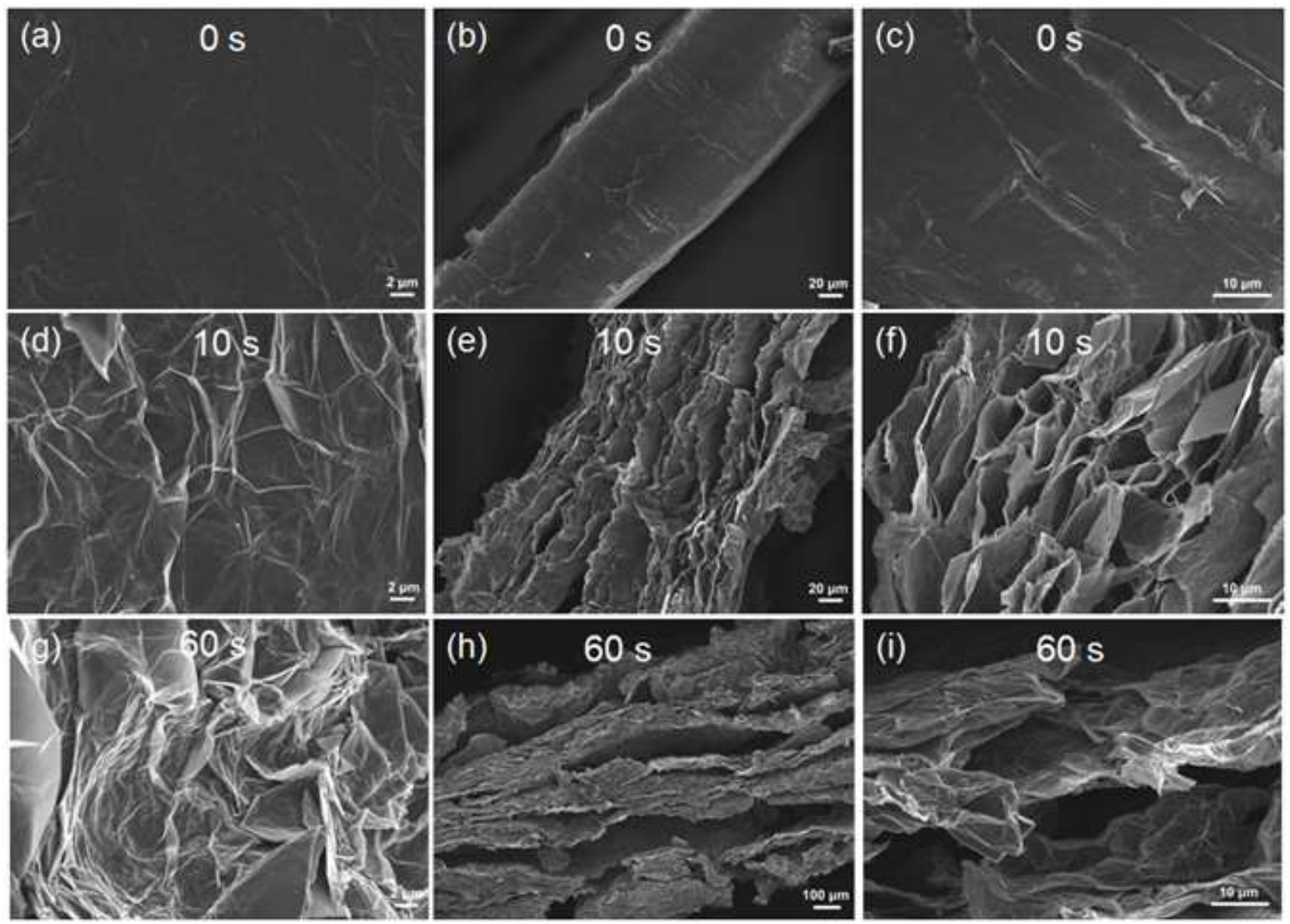

Figure 2. SEM images of (a), (d), and (g) surface and (b), (e), and (h) edge morphology of the graphite foil after applying a bias voltage of $+10 \mathrm{~V}$ for $0 \mathrm{~s}, 10 \mathrm{~s}$, and $60 \mathrm{~s}$ in aqueous $(\mathrm{NH} 4)_{2} \mathrm{SO}_{4}$ electrolyte solution, respectively. (c), (f), and (i) are magnified images of (b), (e), and (h), respectively. 

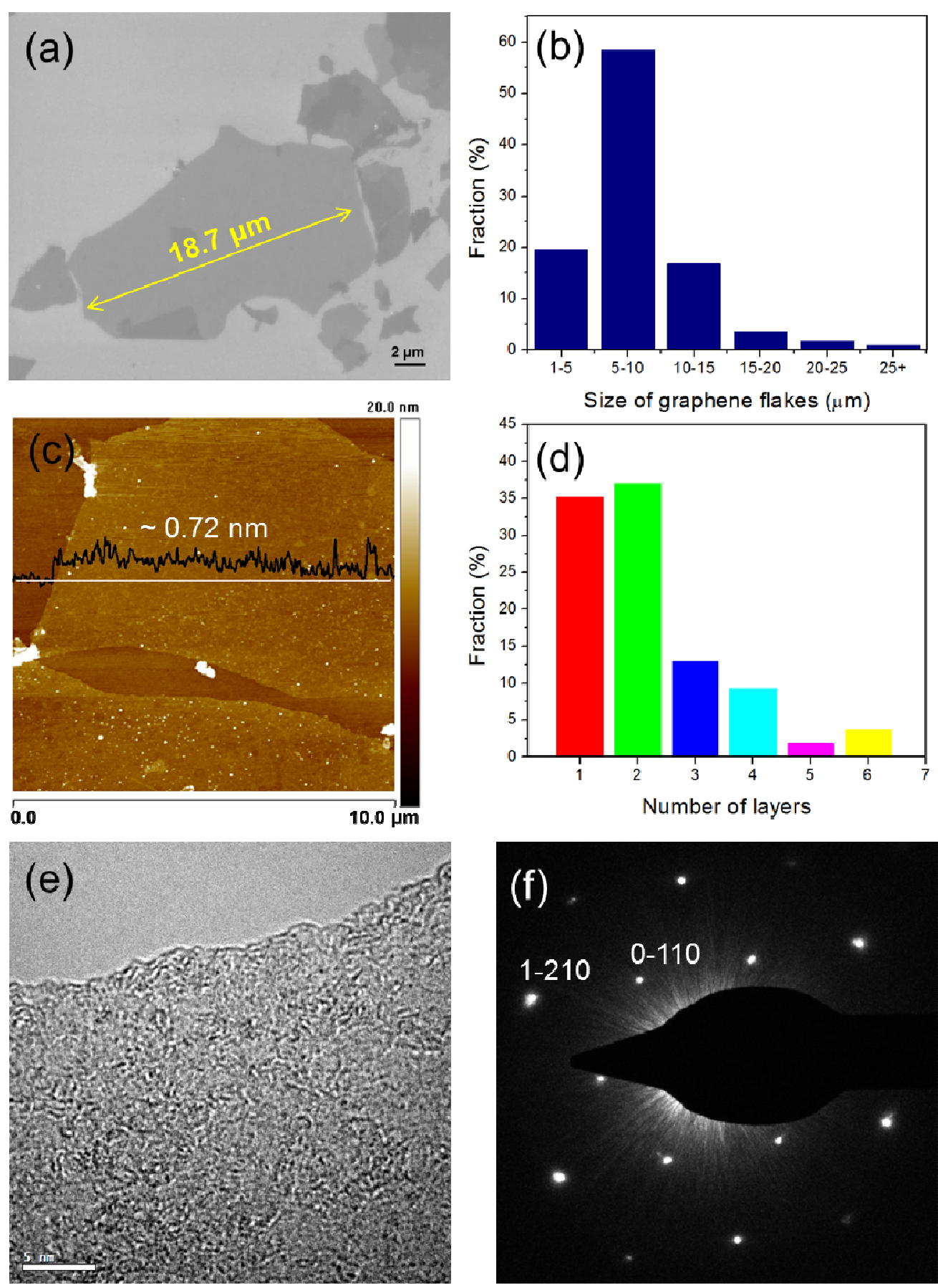

Figure 3. (a) SEM image of EG, (b) statistical flake size analysis of graphene sheets by SEM. (c) AFM image of EG on silicon substrate, (d) statistical thickness analysis of EG by AFM. (e) HRTEM of single-layer graphene. (f) SAED pattern of EG. 

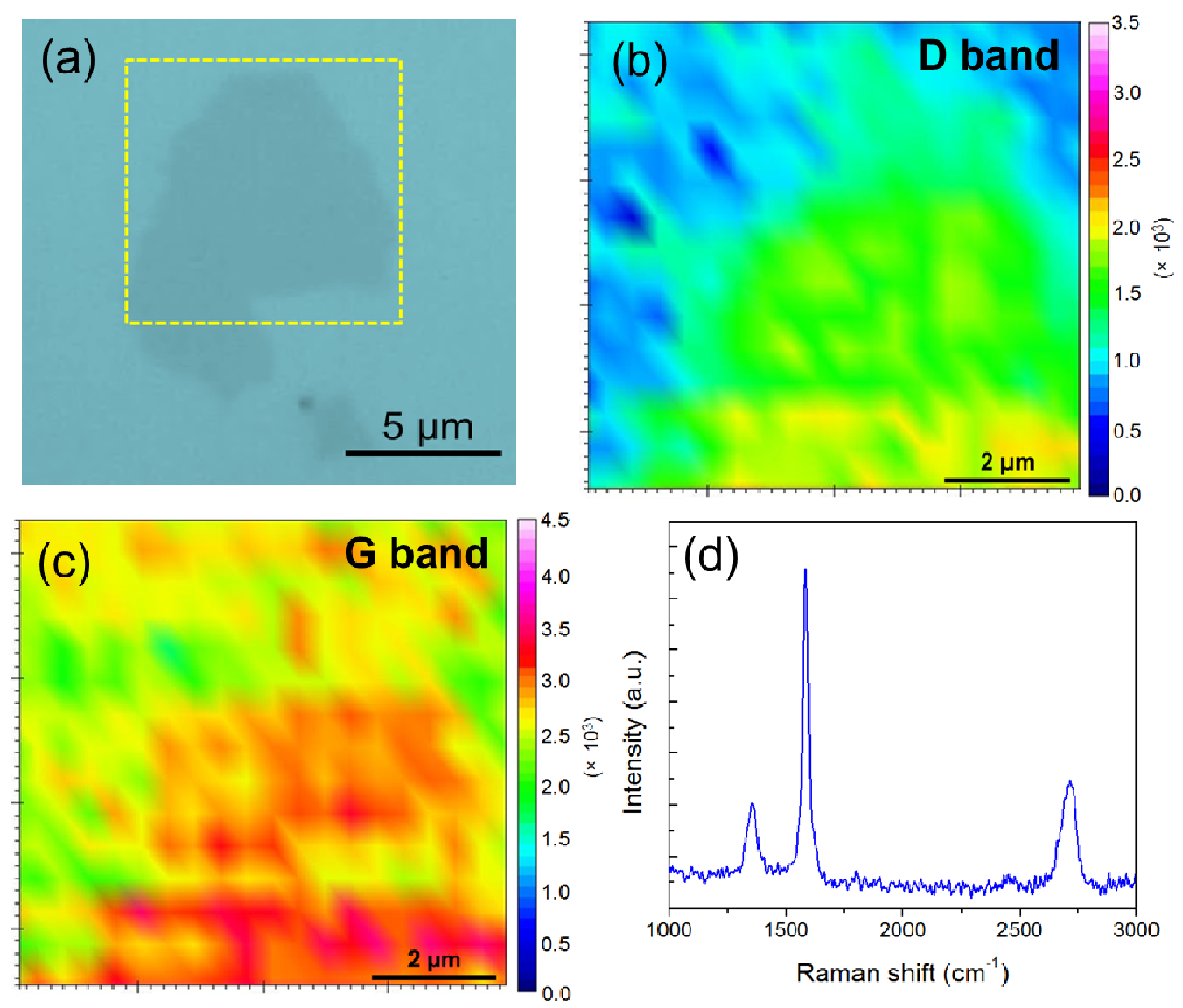

Figure 4. (a) Optical microscopic image of an EG flake. Scale bar $5 \mu \mathrm{m}$. (b) and (c) Raman intensity maps for D and G peak, respectively. (d) Representative Raman spectra. The Raman excitation laser wavelength is $532 \mathrm{~nm}$. 

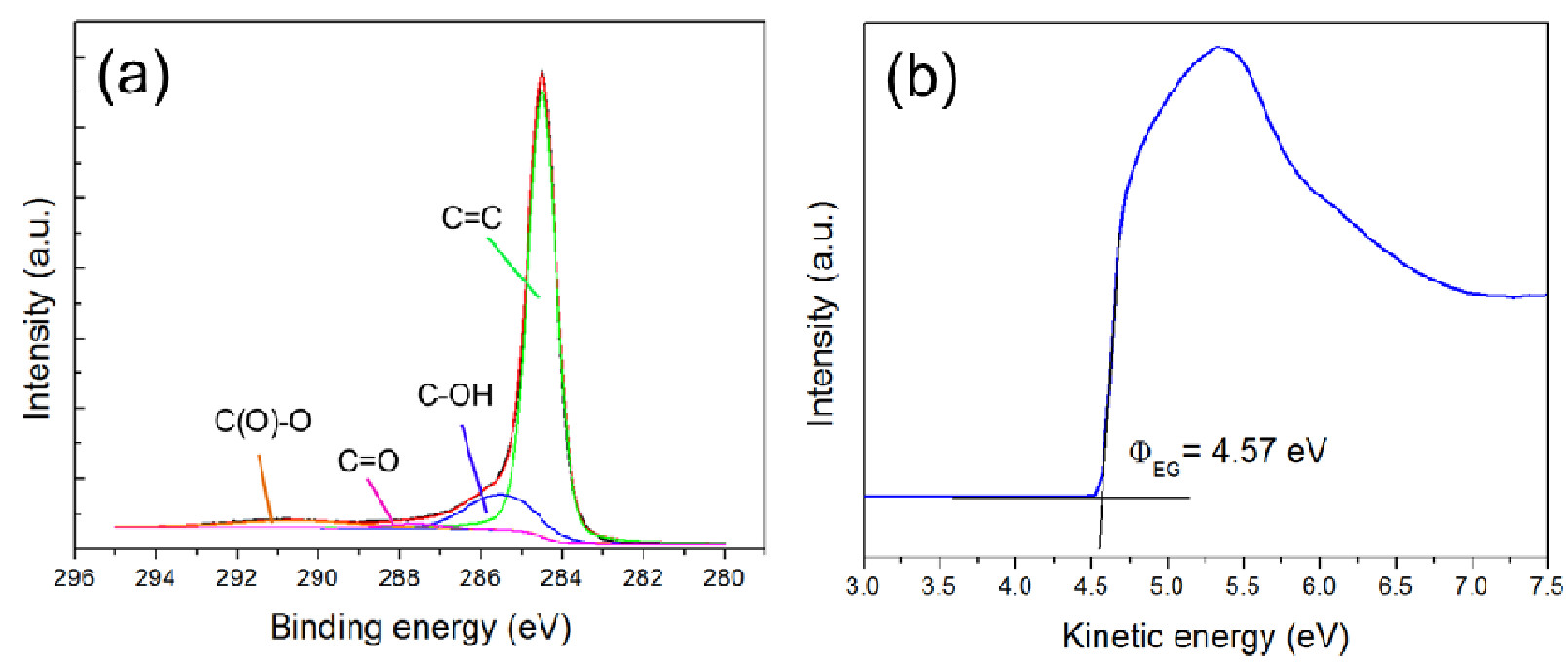

Figure 5. (a) XPS C1s spectra of EG. (b) The secondary electron cut-off of EG measured from ultraviolet photoemission spectra. 


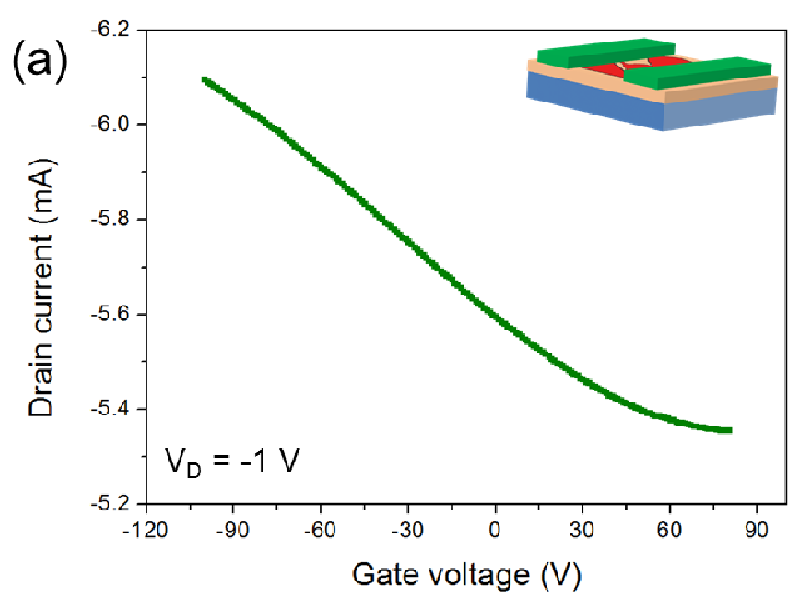

(b)
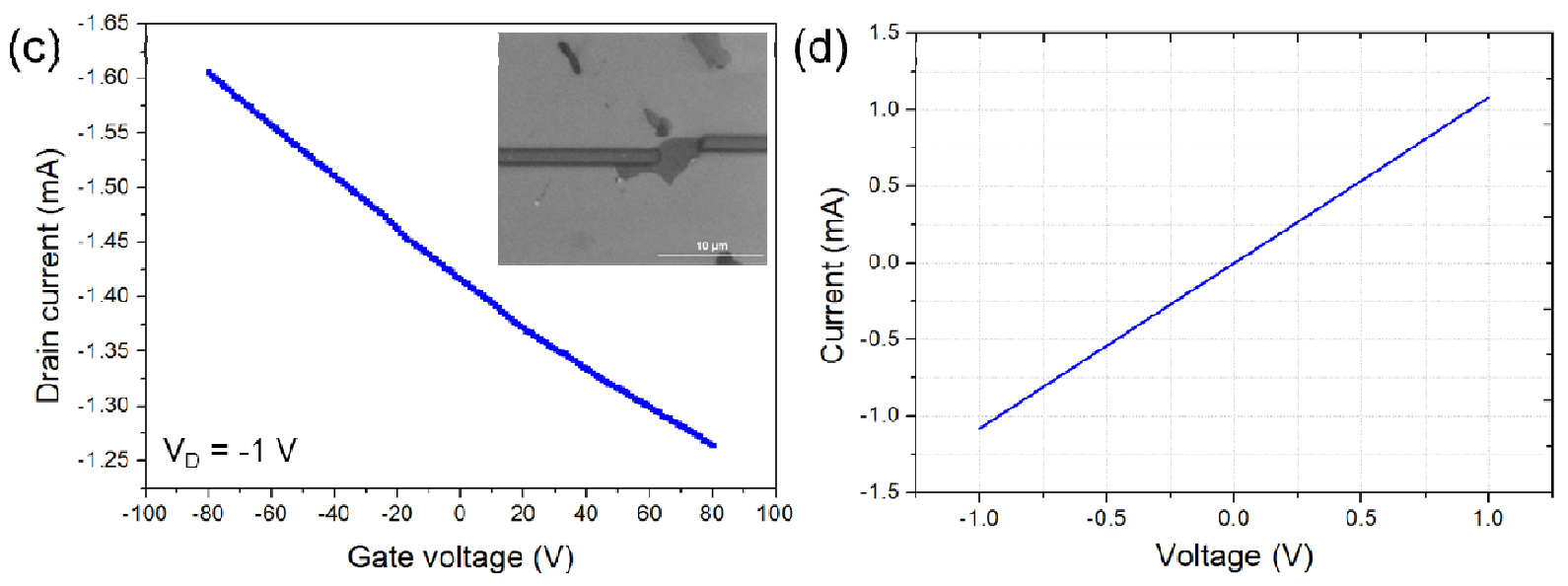

Figure 6. (a) Transfer curve for a FET device based on EG thin film. (b) SEM image of the fabricated device showing thin EG flakes between the Au electrodes. Channel length and width are indicated by arrows. (c) Transfer curve of an FET device based on single-layer EG (inset is the SEM image of the fabricated device). (d) Current-voltage (I-V) curve of an isolated singlelayer EG flake. 

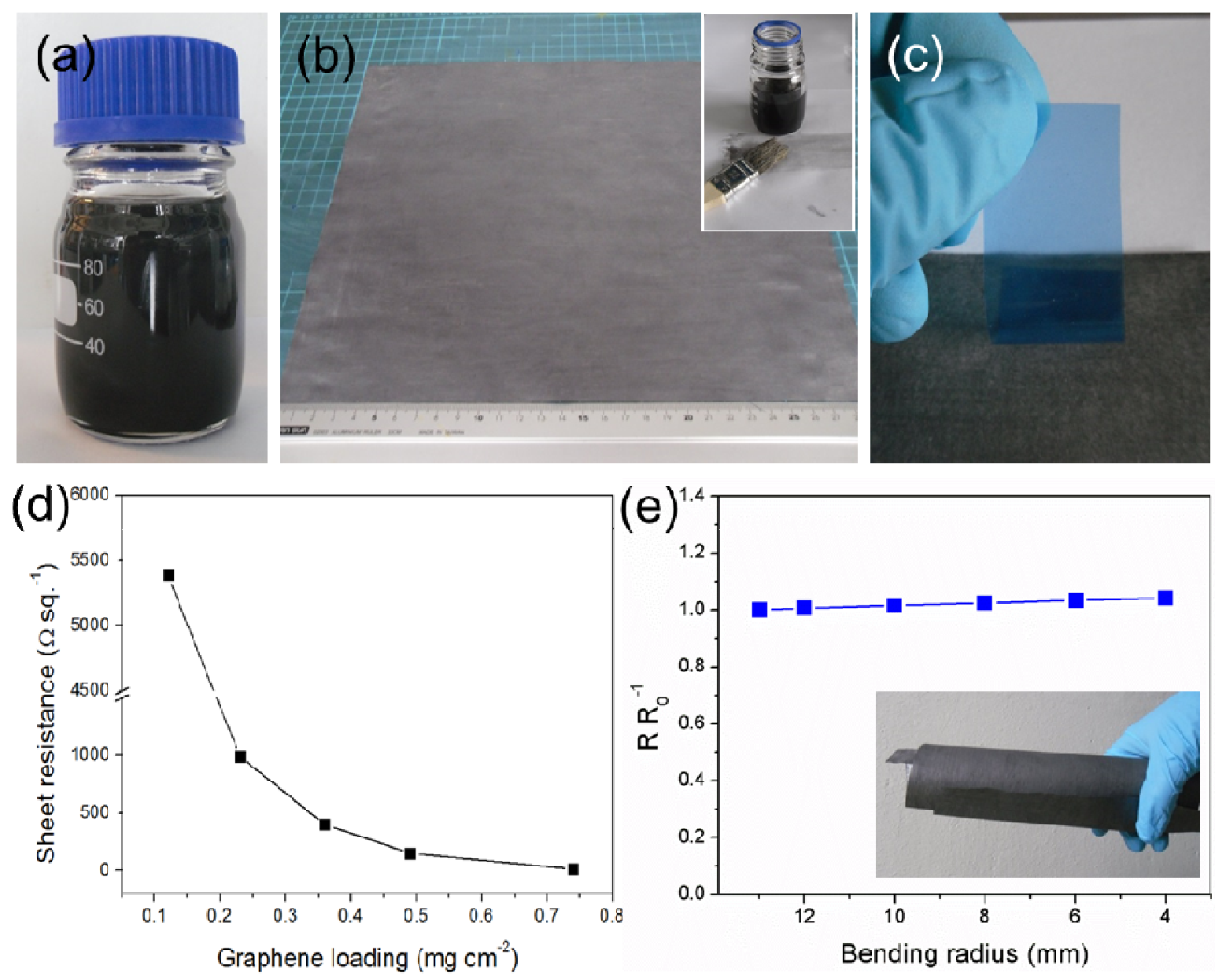

Figure 7. (a) Photograph of EG in DMF (10 mg/mL) used as an ink; (b) commercial A4-size paper coated with EG using a paintbrush (inset). (c) Film adhesion test with cellophane tape (d) Relationship between the resistances of the paper with graphene loading. (e) Changes in sheet resistance after bending the conductive paper into different radii. 
(a)

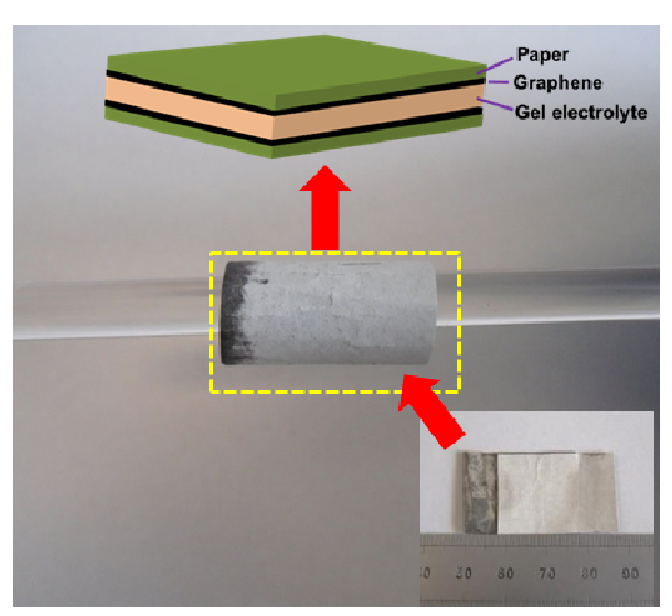

(c)

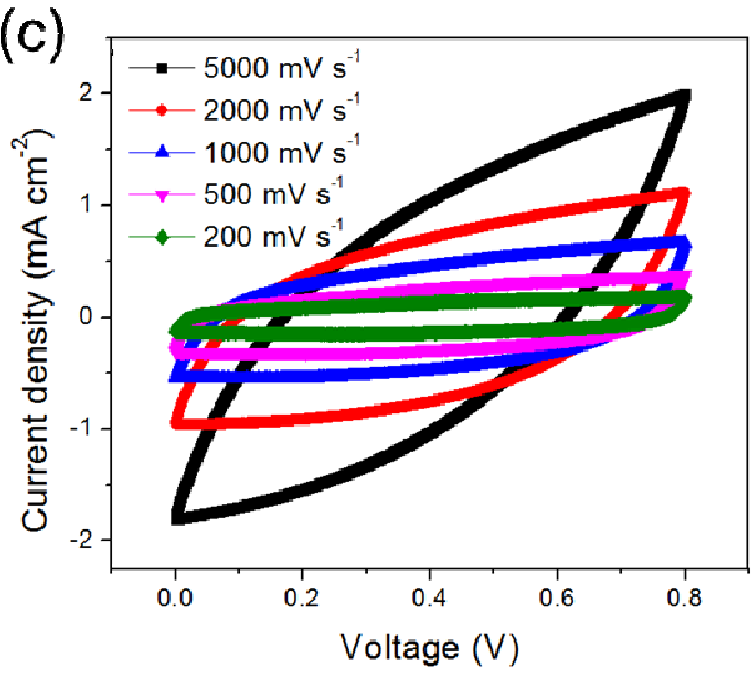

(b)

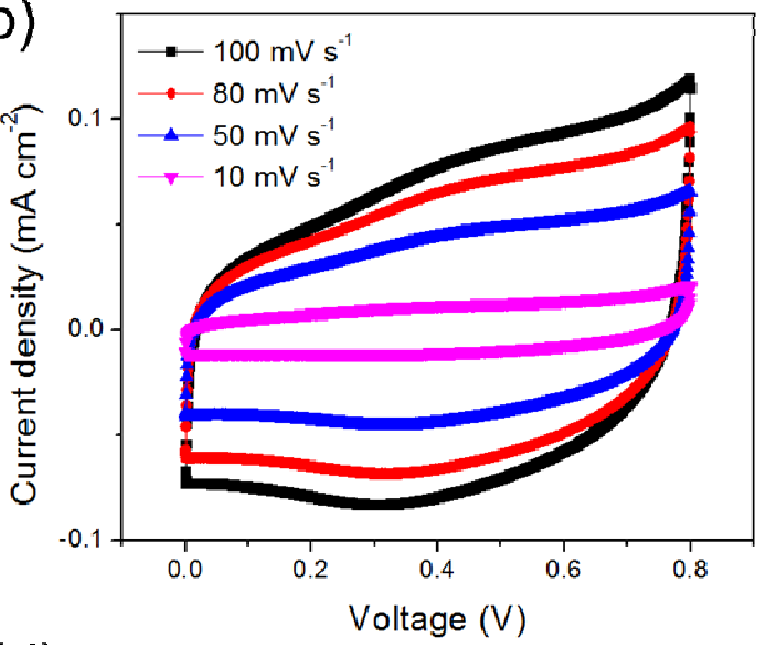

(d)

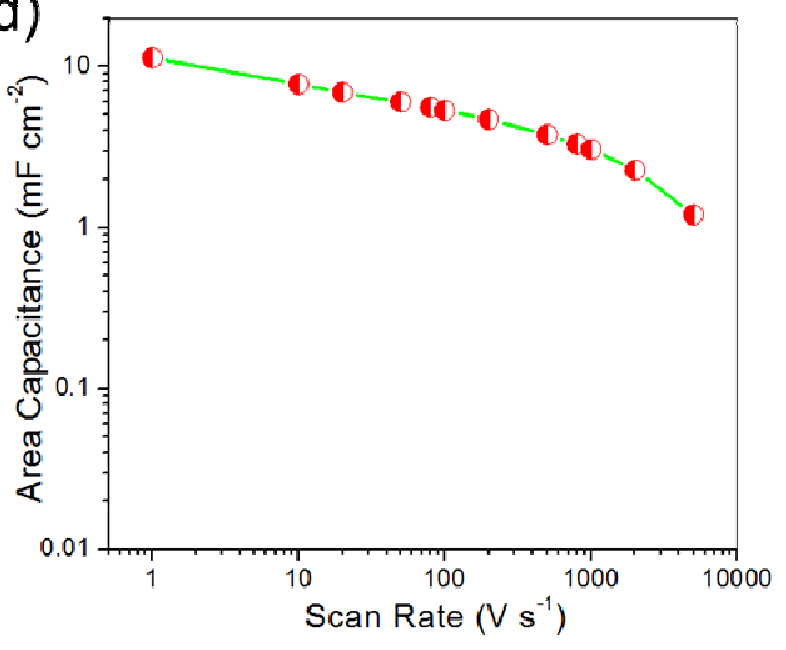

Figure 8. (a) Photographs of supercapacitor based on EG ink-coated paper, where the device is rolled around a glass rod. Inset shows a photograph of the device prior to rolling. (b) and (c) Cyclic voltammetry curves of EG paper based supercapacitor (loading $0.6 \mathrm{mg} \mathrm{cm}$ ) at a scan tares from 10 to $100 \mathrm{mV} \mathrm{s}^{-1}$ and 200 to $5000 \mathrm{mV} \mathrm{s}^{-1}$, respectively. (d) Evolution of area capacitance versus scan rate. 


\section{TOC image}

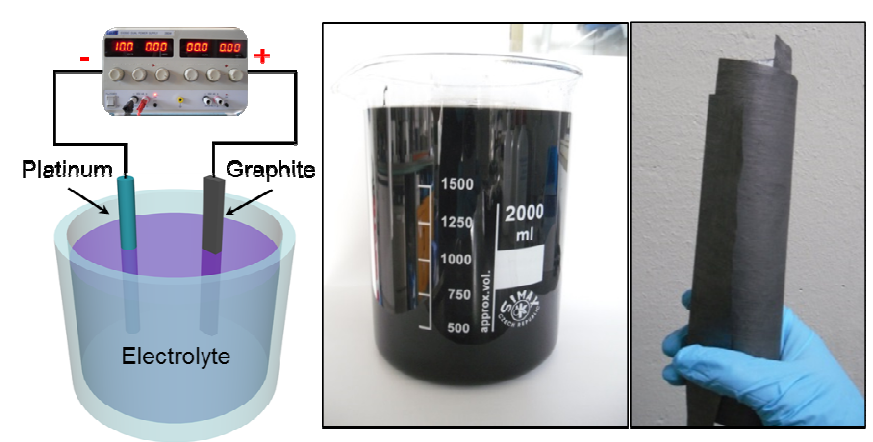

17

18

19

20

21

22

23

24

25

26

27

28

29

30

31

32

33

34

35

36

37

38

39

40

41

42

43

44

45

46

47

48

49

50

51

52

53

54

55

56

57

58

59

60 